\title{
Influence of Façade Configuration on Thermal Performance of Residential Unit of Typical Walk-up Flats in Surabaya
}

\author{
Apriliana Hidayati Nurdin, I Gusti Ngurah Antaryama, and Sri Nastiti Nungrahani Ekasiwi \\ Department of Architecture, Institut Teknologi Sepuluh Nopember, Surabaya \\ e-mail: aprilianahidayati.ah@gmail.com
}

\begin{abstract}
Abstrak-Flat design has evolved and taken many shapes and forms. Most of the arrangements are arranged in a double-load layout where the units are positioned face to face along the corridor. Another type is two single-loaded flats that are configured to face the courtyard. Building façade also varies from those with shaded surfaces to those with minimum sun protection. Modification in design clearly has an impact on the thermal performance of the buildings. The aim of the study is to investigate the facade configuration on the thermal performance of the building. This study uses simulation software, namely, Design Builder, to predict the thermal performance of the buildings. Several variants of window areas, sun shading, balconies are arranged to explore their effects on thermal performance. Flat with yard selected as a reference model. The results showed that the smaller the window area and the greater coverage given to the window with a shading device, combined with the balcony, can provide a decrease in air temperature up to $0.57^{\circ} \mathrm{C}$, with a reduction in cooling degree hours percentage of $36.97 \%$ comparing to the reference model.
\end{abstract}

Kata Kunci-Balcony Configuration, Shading Devices, Thermal Performance, Tropical Building, Window Area.

\section{INTRODUCTION}

$I_{1}^{N}$ N RECENT years, large windows are popular in flats. Large windows are considered to be able to give a broad impression and a better living environment. On the other hand, the greater the transparent field in the facade has the worse effect of thermal performance of space. Nowadays, the shade function of sunscreen devices and balconies is diminishing, compared to previous flats. Therefore needed a passive control strategy with solar control of the facade elements on the thermal performance of space. Several previous studies regarding the investigation of facade elements on thermal performance have been conducted. These studies discuss the solar control strategy of the facade elements [1-3]. WWR (window to wall ratio) also plays an important role in significant energy savings (up to 50\%) for the heating, cooling and lighting loads of buildings. The research conducted by F. Goia et.all, presents the most optimal percentage of the transparent area that is $35-45 \%$ for office buildings [4]. The research uses an air conditioning system with HVAC, located in temperate oceanic climates. Other similar studies with multilevel residential building objects have been carried out in tropical climates. One of them is research by $\mathrm{S}$. Tong et all, on experimental studies with measurements in the field in residential buildings [5]. The building has current residential characteristics, with a

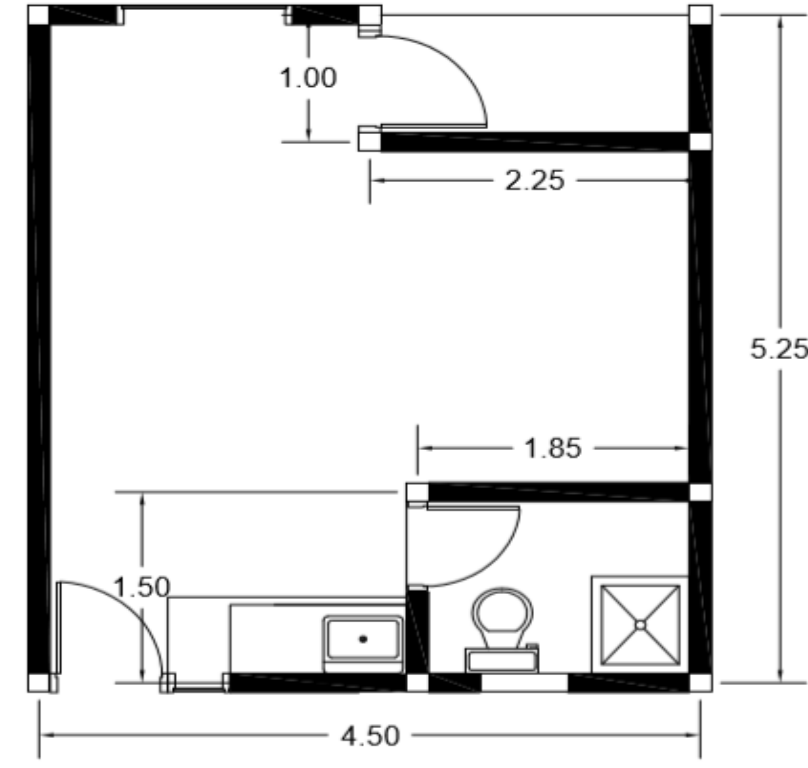

Figure 1. Floor plan of the Siwalankerto flats unit 2.

large window area. This research aims to evaluate the temperature of the air around the facade area due to the influence of the building facade design.

Sunscreen or shading devices can also affect the thermal performance of space. One of the researches about sunscreen was done by S. Liu et. all [6]. This study aims to propose a sunscreen device and evaluate the potential for energy savings. The study was conducted in summer conditions with the help of a simulation program. This research focuses on sunscreens for opaque facade areas, not for shading in the window area. The following studies also discuss the effectiveness of sunscreen configuration [7-8].

Studies on the combination of WWR and sunscreen have been implemented, with solar control strategies for building energy acquisition. In L. S.-L. Rendona et.all which supports the most effective recovery to increase energy savings, as well as natural lighting balance and visibility [9]. The variables reviewed consisted of the self-shading facade, shading devices, window-to-wall ratios and building installations. Development Strategy which is implemented in accordance with the area for subtropical and temperate zones, another research in A. Ghosh et.all a warm and humid climate in Kolkata, India, discuss the influence of geometric factors such as the ratio of windows to walls (WWR), hence, uses of external sunscreen devices to reduce the annual energy consumption of buildings [10]. 
The $6^{\text {th }}$ International Seminar on Science and Technology (ISST) 2020

July $25^{\text {th }}$ 2020, Institut Teknologi Sepuluh Nopember, Surabaya, Indonesia

The balcony is one of the facade elements that can be used has been unable to control the heat entering the space. It is

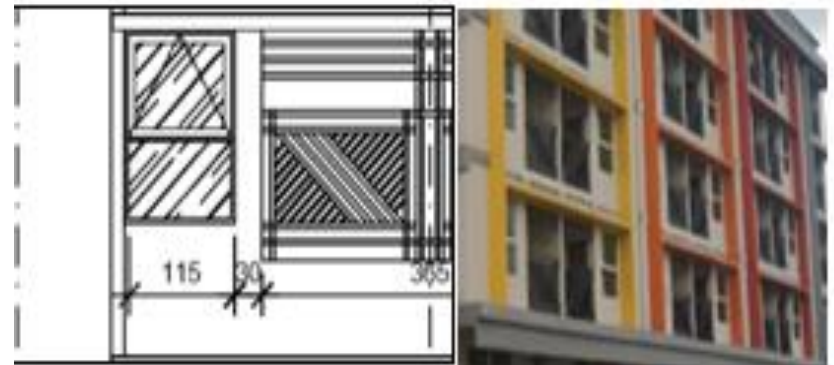

(a)

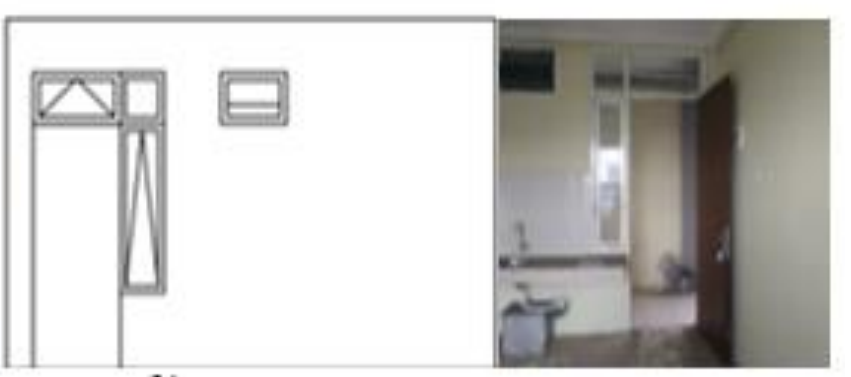

(b)

Figure 2. (a) outer facade; (b) Opening and door to the corridor.

Table 1.

Simulation data input

\begin{tabular}{|c|c|}
\hline Object & Simulation input \\
\hline \multicolumn{2}{|c|}{ Activity Template: Domestic Bedroom, Residential } \\
\hline Occupancy & 0,105 people / m2 \\
\hline Occupancy Pattern & $\begin{array}{l}\text { For weekdays } \\
\text { Until: 7:00, 100\%, } \\
\text { Until: 8:00 a.m., } 50 \% \text {, } \\
\text { Until: 9:00, 25\%, } \\
\text { Until: 5:00 p.m., } 0 \text {. } \\
\text { Until: 11:00 p.m., } 25 \% \text {, } \\
\text { Until: 24:00, 100\%, }\end{array}$ \\
\hline Metabolic & Factor 0,90 \\
\hline Clothing & 0,5 clo \\
\hline $\begin{array}{l}\text { Lighting } \\
\text { Construction }\end{array}$ & Target Illuminance: 150 Lux. General lighting: Normalised Power density: $3 \mathrm{~W} / \mathrm{m}^{2}-100$ Lux \\
\hline External Wall & $15 \mathrm{~cm}$ brick wall, 3 layers, U-Value: $2,643 \mathrm{~W} / \mathrm{m} 2-\mathrm{K}$, R-Value: $0.378 \mathrm{~m} 2-\mathrm{K} / \mathrm{W}$ \\
\hline Window & Single clear $6 \mathrm{~mm}$ glazing, with aluminium window frame, U-Value: $5,77 \mathrm{~W} / \mathrm{m}^{2}-\mathrm{K}$, Total solar transmission 0,819 \\
\hline Floor & Concrate slab 100mm, 2 layer, with ceramic, U-Value: $2,864 \mathrm{~W} / \mathrm{m}^{2}-\mathrm{K}$ \\
\hline $\begin{array}{l}\text { Roof } \\
\text { Natural Ventilation }\end{array}$ & Unoccupied pitched roof, U-Value: $0,192 \mathrm{~W} / \mathrm{m}^{2}-\mathrm{K}$ \\
\hline HVAC & Natural Ventilation- No Heating/cooling \\
\hline
\end{tabular}

as an object of a passive design control strategy. The balcony located in the front area of the opening is considered to have a cooling effect on the space inside It occurs by relying on the physiological influence of the movement of the wind, according in S. Omrani, V. et.all, discuss thermal comfort in naturally ventilated buildings using balconies [11]. The aim is to investigate the effect of balconies on the natural ventilation performance and thermal comfort of residential buildings. On the other hand A. L. S. Chan et.all, states that the balcony can act as a shade provider, in terms of saving electrical energy from the room's air conditioning system [12]. The study was conducted in Hong Kong, with the object of a living room balcony. The variables studied were in the form of building orientation and window glass material. The results obtained are flats with various orientations that are more energy efficient with the shading effect from the balcony.

Research on solar control strategies on building facade elements, in particular, WWR and sun shading, Many studies have been conducted to investigate thermal performance. Facade elements in flats in Surabaya continue to experience growth and change. Changes to the facade configuration that occur are the reduction in shade devices such as sunscreens and balconies, but the transparent area in the openings is getting wider. Changes to the facade of this apartment building still have problems. The design of the facade to date still rare research that discusses the influence of typical changes in the current design of the facade of the current apartment, which is combined with some facade elements from previous types of flats. Facade elements studied are sunscreen configurations, balconies and comparison of different WWR areas. This study aims to evaluate the effect of facade configuration on the thermal performance of residential units in apartment buildings.

\section{METHOD}

Analysis and completion, also the proposed method of the study is carried out using simulations namely Design Builder to see the facade configuration that is most effective against the thermal performance of space. Design Builder uses the thermal equilibrium method to estimate the thermal performance of buildings. Previous studies have used experimental methods with simulations to find the best performance from thermal performance and building energy acquisition[6][10]. The independent variables used in this study are WWR configuration, sunscreen configuration, and balcony configuration. Dependent variables measured include air temperature, humidity, and wind speed.

\section{A. Building Description}

The object of research is the Siwalankerto flats located on 


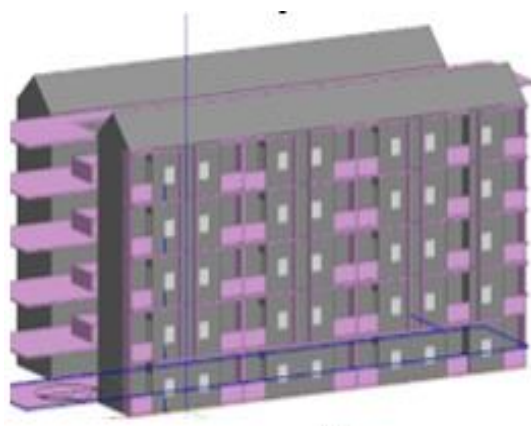

(a)

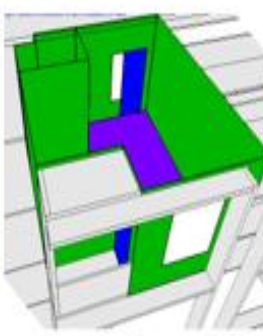

(b)
Figure 3. (a) reference model; (b) floor plan.

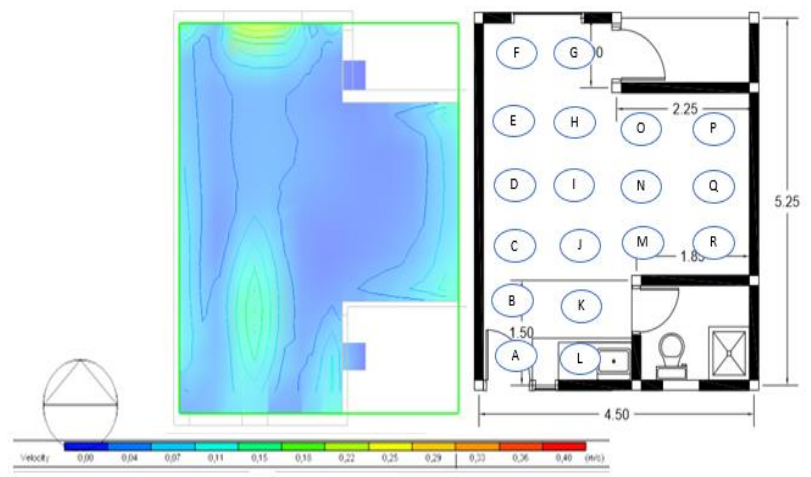

Figure 4. Wind speed at the reference point on the floor.

East Siwalankerto V Mulyosari road, Wonocolo Sub-district, Surabaya, East Java 60236. The Siwalankerto 2 flats unit is a type of studio unit with an open plan system, can be seen in the figure. 1. The object of research is on the 5th floor, with an area of $4.5 \mathrm{~m} \times 5.25 \mathrm{~m}$. The layout of the space in the layout of the apartment unit is following the typology study, which has a balcony on the side. But for the location of the kitchen is not front of the balcony area but adjacent to the entrance. The front facade of the flat consists of one large window, measuring $115 \mathrm{~cm}$ x $180 \mathrm{~cm}$ divided into two types of windows. The first window is at the top with the type of awning window measuring $115 \mathrm{~cm} \times 90 \mathrm{~cm}$, while at the bottom is a window with the same size of fix glass. While the facade in the corridor has a door and window with awnings, measuring $40 \mathrm{~cm} \times 150 \mathrm{~cm}$. The building facade has sunscreen, namely horizontal and 1 vertical overhang with a length of $0.4 \mathrm{~m}$ show in Fig. 2

\section{B. Experiments and Simulation}

The simulation procedure is carried out with the first step which is to determine the location of the simulation and enter local climate data. The research location is in the city of Surabaya with an ordinate point of $2.71^{\circ} \mathrm{S}$ and $112.715^{\circ} \mathrm{E}$. The second step is to make the simulation model building according to the reference model. Furthermore to do the settings for simulation data input, ranging from activities, construction, and natural ventilation systems. Then enter the thermal simulation stage to find the value of air temperature, humidity and wind speed in the space being tested. Data from simulation results taken in the form of an average of every hour for 24 hours.

The existing building is used as a reference for the reference model in research. The building model in the
Table 2 .

Facade element configuration

\begin{tabular}{|c|c|}
\hline $\begin{array}{l}\text { Experimental } \\
\text { Model }\end{array}$ & Components of facade elements \\
\hline $\begin{array}{l}\text { Reference model } \\
(\mathrm{RM})\end{array}$ & $\begin{array}{l}\text { WWR } 26 \% \text {, horizontal-vertical overhangs } \\
\text { with a length of } 0.4 \mathrm{~m} \text {, open balcony with a } \\
\text { depth of } 20 \% \text {. }\end{array}$ \\
\hline $\begin{array}{l}\text { Facade configuration } \\
1(\mathrm{FC}-1)\end{array}$ & $\begin{array}{l}\text { WWR } 10 \% \text {, horizontal-vertical overhangs } \\
\text { with a length of } 0.8 \mathrm{~m} \text {, semi-enclosed } \\
\text { balcony with a depth of } 30 \% \text {. }\end{array}$ \\
\hline $\begin{array}{l}\text { Facade configuration } \\
2(\mathrm{FC}-2)\end{array}$ & $\begin{array}{l}\text { WWR } 30 \% \text {, horizontal overhangs with a } \\
\text { length of } 0.4 \mathrm{~m} \text {, open balcony with a depth } \\
\text { of } 10 \% \text {. }\end{array}$ \\
\hline $\begin{array}{l}\text { Facade configuration } \\
3(\mathrm{FC}-3)\end{array}$ & $\begin{array}{l}\text { WWR } 20 \% \text {, vertical overhangs with a } \\
\text { length of } 0.6 \mathrm{~m} \text {, semi-enclosed balcony } \\
\text { with a depth of } 20 \% \text {. }\end{array}$ \\
\hline $\begin{array}{l}\text { Facade configuration } \\
4(\mathrm{FC}-1)\end{array}$ & $\begin{array}{l}\text { WWR } 10 \% \text {, horizontal-vertical overhangs } \\
\text { with a length of } 0.8 \mathrm{~m} \text {, open balcony with a } \\
\text { depth of } 20 \% \text {. }\end{array}$ \\
\hline
\end{tabular}

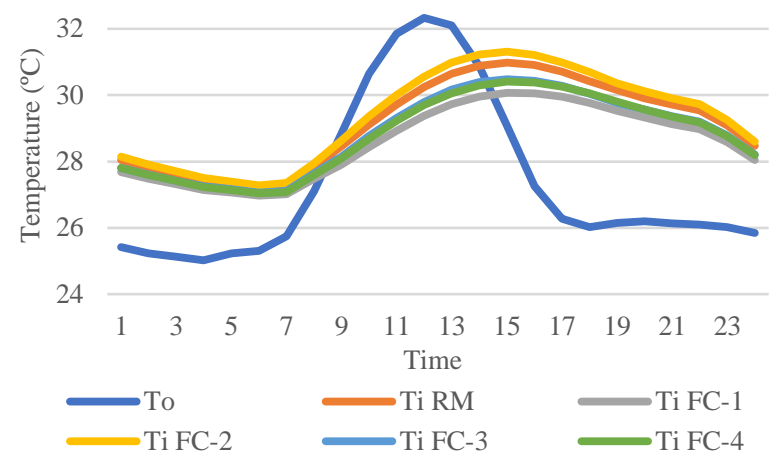

Figure 5. Influence of facade configuration on room temperature profiles.

simulatio $\mathrm{n}$ is made similar to the facade of the reference model which has a $40 \mathrm{~cm}$ long overhang, with a horizontal overhang type and 1 vertical overhang side. The building plan of the model has an area of $4.5 \times 5.25 \mathrm{~m}$ it can be seen in Figure 3. The components of the simulation data input in Table 1.

Wind speed in space can be known from the CFD simulation results, by looking at the wind distribution of each reference point on the floor plan as in Figure. 4. Configuration of facade elements used as simulation models of 4 models, and 1 reference model. The arrangement of facade element components in the facade configuration model can be seen in Table 2 .

Equation (1) represents to get a neutral temperature (Tn) from a range of acceptable comfort conditions that range from $(\mathrm{Tn}-2.5){ }^{\circ} \mathrm{C}$ to $(\mathrm{Tn}+2.5){ }^{\circ} \mathrm{C}$ [13]. The range limit of $\mathrm{Tn}$ can be used as a reference for the base temperature on $\mathrm{CDH}$ :

$$
\operatorname{Tn}=17,6+(0,31 \times \text { To.average })
$$

Where

Tn = Neutral temperature

To = Average outdoor temperature

Equation (2) represents to get a cooling degree hour, which can be calculated by adding up the difference between of drybulb temperature or the hourly indoor temperature and the standard reference temperature (base temperature)[13].

$$
\mathrm{CDH}=\sum(\mathrm{Ti}-\mathrm{Tb})
$$


The $6^{\text {th }}$ International Seminar on Science and Technology (ISST) 2020

July $25^{\text {th }} 2020$, Institut Teknologi Sepuluh Nopember, Surabaya, Indonesia

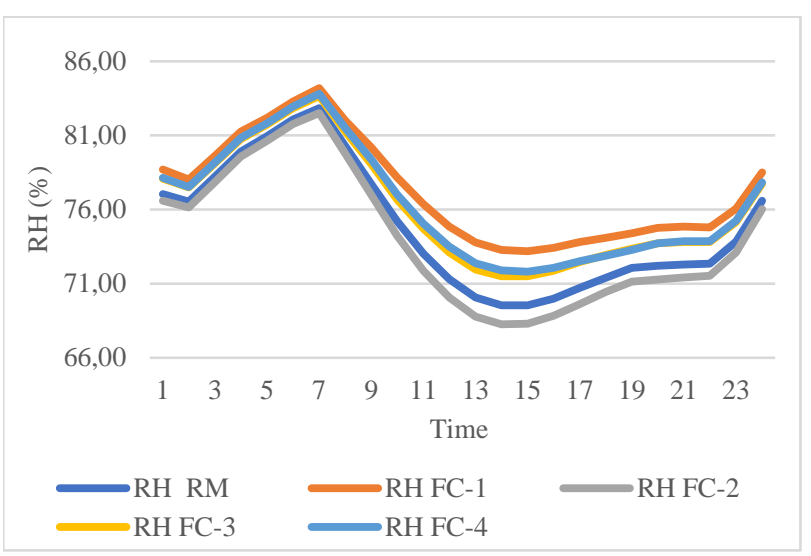

Figure 6. Influence of facade configuration on room humidity.

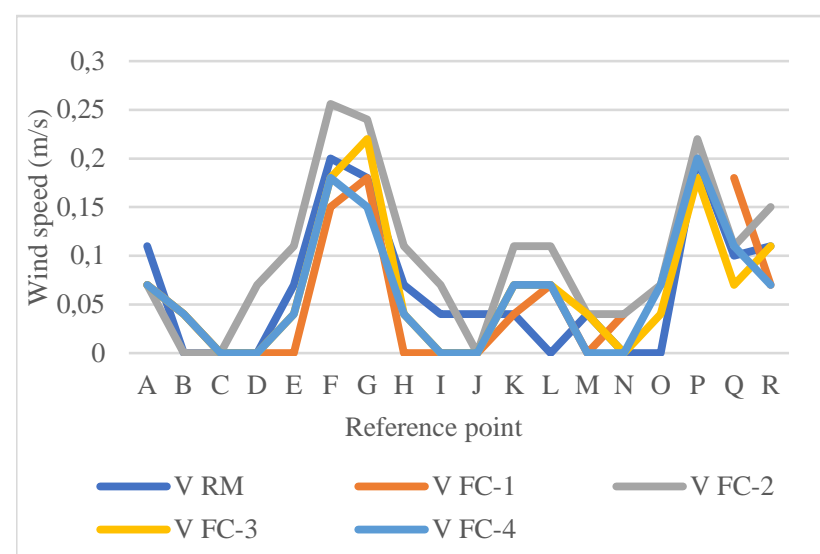

Figure 7. Influence of facade configuration on wind speed.

Whe re

$\mathrm{N}=$ Number of hours in a day,

$\mathrm{Tb}=$ The base temperature at which degree-days are calculated,

$\mathrm{Ti}=$ Average temperature per hour.

Equation (3) represents to get the minimum wind speed requirements in certain temperature and humidity conditions [14]:

$$
\text { WSc }=0,15(\text { DBT-27,2 }+0,56(\text { RH-60) } / 10
$$

Where

WSc $=$ Required wind speed $(\mathrm{m} / \mathrm{s})$

To $=$ Average temperature $\left({ }^{\circ} \mathrm{C}\right)$

$\mathrm{RH}=$ Humidity $(\%)$

\section{RESULTS AND DISCUSSION}

This study was simulated using weather data from the city of Surabaya, Indonesia, which has a humid tropical climate. Previous climate data in 2019 can be used as a reference in research. The average air temperature is $28.1{ }^{\circ} \mathrm{C}$, with an average humidity of $76 \%$. The average wind speed ranges from 6.4 to $7.8 \mathrm{~m} / \mathrm{s}$, with the dominant wind direction towards the East. The hottest month is November with an average temperature of $30.2^{\circ} \mathrm{C}$, and the maximum temperature reaches $34.6^{\circ} \mathrm{C}$. However in this hottest month, the humidity has decreased with a value of only $60 \%$. The coldest month occurred in March with an average temperature of $27.7^{\circ} \mathrm{C}$ and humidity of $74.5 \%$.

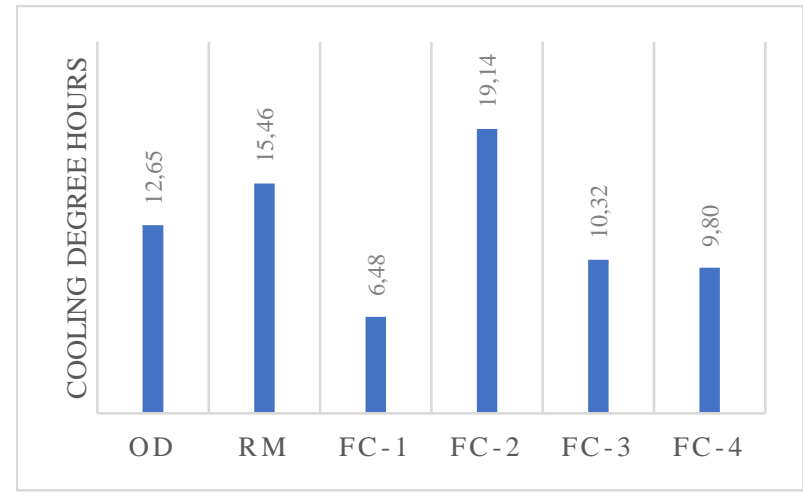

Figure 8. Thermal performance of cooling degree hours.

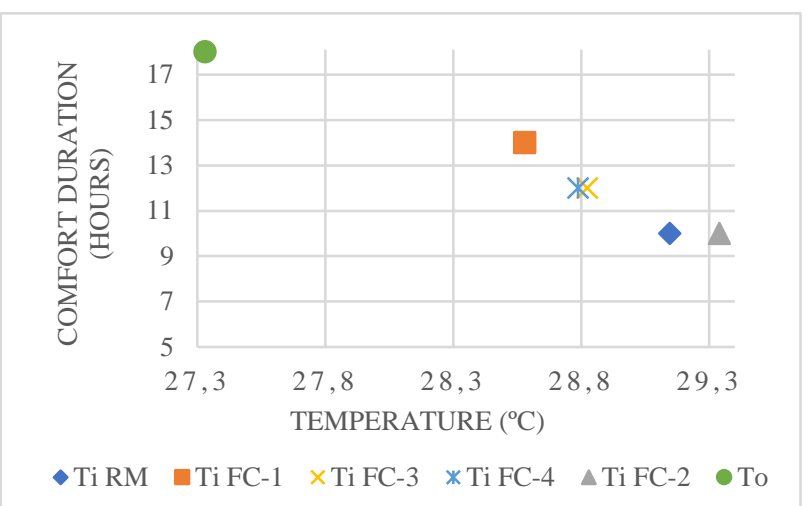

Figure 9. Temperature average of the duration of thermal comfort.

\section{A. Inf luence of facade configuration on temperature profiles, humidity and wind speed}

The temperature profile represented in Fig. 5. The air temperature in the room shows quite different results between the facades configuration 1 and 2 . At the time of the hot peak during the day that is at 15:00, the air temperature in the facade configuration models 1,3 and 4 have quite a large difference to the reference model. Facade configuration 1 model has a temperature difference of $0.91^{\circ} \mathrm{C}$, facade configuration model 3 has a difference of $0.50^{\circ} \mathrm{C}$ and facade configuration 4 model has a difference of $0.57^{\circ} \mathrm{C}$ lower than the reference model. As for the facade configuration 2 model, it experiences an increase in air temperature when compared to the reference model with a difference of $0.33^{\circ} \mathrm{C}$. This is in line with the significant increase in temperature outside the building and reaches its peak at $12.00 \mathrm{PM} 32.33{ }^{\circ} \mathrm{C}$.

The humidity graph show in Figure 6. Humidity starts experiencing a decrease in fluctuations in the morning until the afternoon, and experiences the lowest peak at 14.00. The difference in the humidity of each facade configuration model compared to the reference model is quite significant during the decline period. The maximum difference value is $3.65 \%$ and the minimum difference is $1.24 \%$ for the reference model. Humidity in the room is inversely proportional to air temperature. This is in line with the occurrence of significant differences between several facade configuration models from 14.00 to 18.00 .

Wind speed at each measuring point in space show in Figure 7. The highest measuring points, $\mathrm{F}$ and $\mathrm{G}$, are the closest point to the opening area. The highest value in the reference model is $0.2 \mathrm{~m} / \mathrm{s}$, which is lower than that of the $\mathrm{f}$ 
The $6^{\text {th }}$ International Seminar on Science and Technology (ISST) 2020

July $25^{\text {th }} 2020$, Institut Teknologi Sepuluh Nopember, Surabaya, Indonesia

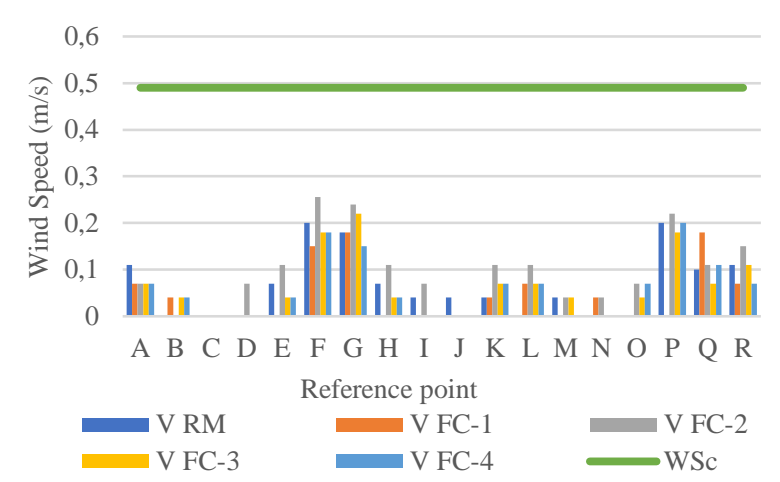

Figure 10. Influence $\mathrm{t}$ of physiological effects of wind on thermal performance.

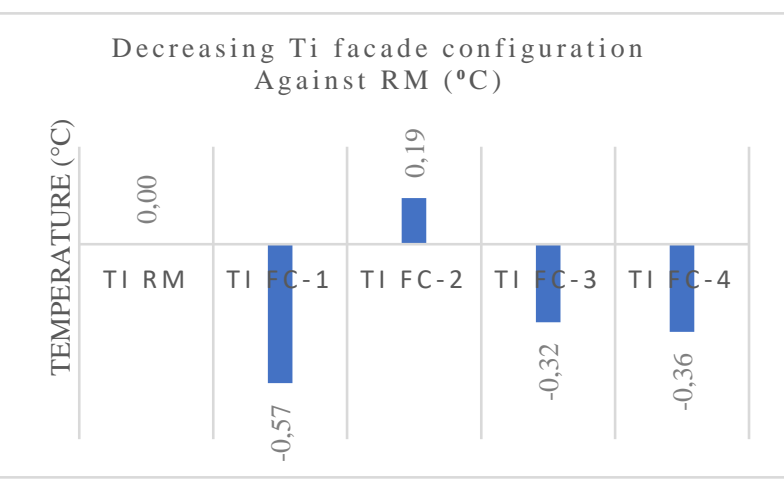

Figure 11. Influence of facade configuration on decreasing room temperature.

acad e 2 configuration model with wind speeds reaching $0.256 \mathrm{~m} / \mathrm{s}$. This is influenced by the wider use of the WWR facade elements $30 \%$. Open balconies with a depth of $10 \%$ also affect the increased flow of airflow in the room. However, when compared to the condition of outdoor wind speeds reaching $4.47 \mathrm{~m} / \mathrm{s}$, the condition of wind speeds is still large enough to be reduced while in the room.

\section{B. Influence of facade configuration on thermal performance}

Regarding the comfort threshold required for thermal performance, the results of the Tn calculation from outdoor temperatures are $26.07^{\circ} \mathrm{C}$, with a lower limit of $24.07^{\circ} \mathrm{C}$ and an upper limit of $28.07^{\circ} \mathrm{C}$. The experimental results show that conditions that enter the comfort range only at certain times. Calculation of cooling degree hours are obtained from equation (2). Figure. 8 discusses the cooling degree hours analysis conducted to determine the amount of difference between the comfort limit temperature and the temperature in the experimental model. The value of cooling degree hours in outdoor conditions is always lower than the reference model. The lowest cooling degree hours are obtained by facade configuration 1 of 6.48 . Instead, the highest value obtained by the facade configuration 2 is 19.14 higher than the reference model of 15.46. Facade configurations 3 and 4 have cooling degree hours values that are not much different at 10.32 and 9.80. The thermal performance of the room on the acquisition of cooling degree hours is better if it has a smaller value.

Fig. 9 shows the duration of comfort obtained based on the aver age value of indoor air temperature. Facade

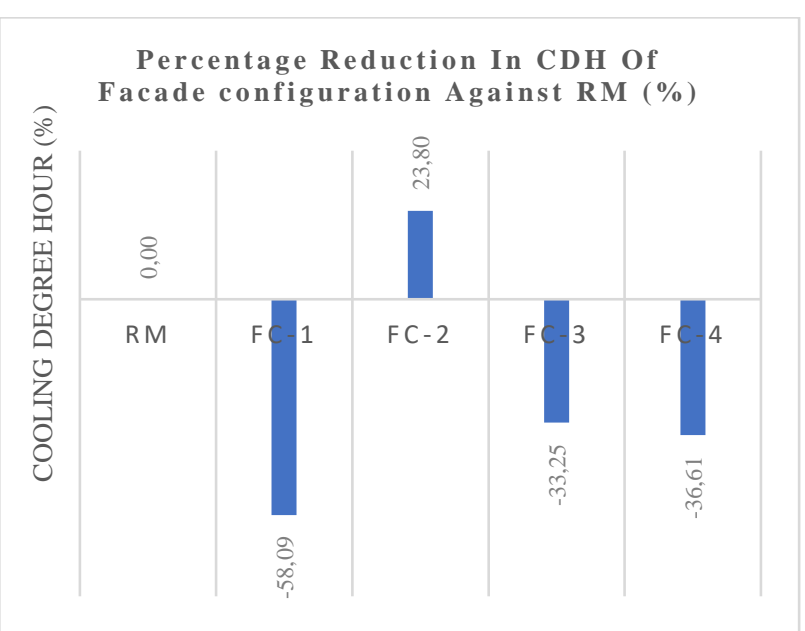

Figure 12. Influence of facade configuration on the percentage decrease in Cooling degree hours.

configuration 1 model has a longer duration of a comfort compar ed to other models, which reaches 14 hours. Two models that have a similar duration of comfort namely facade configuration 3 and 4 for 10 hours. Another case in facade configuration 2 model has a shorter duration of a comfort compared to the reference model that is only for 8 hours, the average value of $\mathrm{Ti}$ for the lowest duration of comfort obtained facade configuration 1 model, as much as $28.57^{\circ} \mathrm{C}$. As for the underperformance obtained the facade configuration 2 model, which has an average value of $29.33^{\circ} \mathrm{C}$ higher than the reference model of $29.14^{\circ} \mathrm{C}$.

Figure. 10 presents the experimental results of the influence of the physiological effects of the wind on thermal performance. The average value of the highest wind speed obtained by facade configuration 2 model is equal to $0.099 \mathrm{~m}$ / s. conversely, the lowest value obtained by the facade configuration 1 model of $0.053 \mathrm{~m} / \mathrm{s}$. The experimental results explain that the combination of a shorter balcony without a hitch with a large WWR shirt can affect wind speeds in the room for the better. The physiological effect will be represented by the value of Wind Support Comfort (WSC), which can be seen in Equation (3). When compared with the WSc (wind support comfort) value of $0.49 \mathrm{~m} / \mathrm{s}$, the wind speed in space still does not meet the minimum limit. But for the facade configuration 2 model can provide an average increase in wind speed in space when compared with the reference model. The condition of temperature and humidity at 15.00 which became the basis of WSc calculation was $30.98^{\circ} \mathrm{C}$ and $69.54 \%$.

\section{Performance Configuration of Facade Elements}

The experimental results of four different facade configuration models, three of which have experienced a decrease in temperature compared to the conditions of the reference model show in Figure. 11. The highest reduction in air temperature is obtained from the facade configuration 1 model, with a reduction in temperature reaching $0.57^{\circ} \mathrm{C}$. Subsequently followed by facades configuration models 3 and 4 , each experiencing a decrease in temperature of $0.32^{\circ} \mathrm{C}$ and $0.36^{\circ} \mathrm{C}$. Based on the results of this experiment, only the facade configuration 2 model experienced an increase in indoor air temperature of $0.19^{\circ} \mathrm{C}$. 
The $6^{\text {th }}$ International Seminar on Science and Technology (ISST) 2020

July $25^{\text {th }} 2020$, Institut Teknologi Sepuluh Nopember, Surabaya, Indonesia

Figure. 12 shows the performance of the facade configuration to the percentage decrease in cooling degree hours for 1 day. A decrease in cooling degree hours can indicate a reduction in the amount of cooling required by the building. The largest decrease in cooling degree hours can be achieved by the facade configuration 1 model of $58.09 \%$ compared to the reference model. On the contrary, the poor performance was obtained by facade configuration 2 , which experienced an increase in the percentage of cooling degree hours of the reference model by $23.80 \%$. Facade configurations 3 and 4 have a not-so-different percentage decrease in cooling degree hours. Facade configuration 3 has a value of $33.25 \%$, while the facade configuration 4 is $36.61 \%$.

\section{Discussion}

Based on the results of experiments performed on facade configuration models, the best results were obtained by facade configuration 1 models on thermal performance. In case facade configuration 1 model has a difference in temperature reduction of $0.57^{\circ} \mathrm{C}$ compared to the reference model. The highest percentage decrease in cooling degree hours by facade configuration 1 is $58.09 \%$. On the other hand, the underperformance of thermal performance in terms of obtaining an increase in indoor air temperature is obtained by case in facade configuration 2 model, which experiences an average rise in temperature of $0.19^{\circ} \mathrm{C}$ compared to the reference model. In addition, the percentage increase in cooling degree hours was also obtained by the facade configuration 2 of $23.80 \%$. The facade configuration 2 model has a wider WWR of $30 \%$, which is responsible for the amount of heat gain in the room. This is according to V. Szokola, which states that the transparent element is a material that can transmit solar heat recovery both by convection and radiation into and outside the building [13]. However, when viewed from the side of wind speed in space, the facade configuration 2 model has the highest average wind speed reaching $0.1 \mathrm{~m} / \mathrm{s}$. The results of experiments using more extensive WWR can increase wind speed, in line with the theory put forward by F. Allard, [15]. Besides the use of balcony elements with an open type and a depth of only $10 \%$ also increases the speed of airflow in the room. This is since the air entering through the facade field is not directly reduced according to the research by S. Omrani, V et.all [11].

Facade configuration models 3 and 4 also have a fairly better performance against the thermal performance of the room. Facade configuration 3 model has a difference in the decrease in air temperature to the reference model of $0.32^{\circ} \mathrm{C}$. facade configuration 4 has a difference in the decrease in air temperature to the reference model of $0.36^{\circ} \mathrm{C}$. The percentage decrease in cooling degree hours was obtained by facades configurations 3 and 4 of $33.25 \%$ and $36.61 \%$. Although the WWR area in the facade 3 configuration model is larger, the use of other shade elements such as a vertical overhang $0.6 \mathrm{~m}$ long and a semi-enclosed balcony with a depth of $20 \%$ can provide adequate shade this corresponds to V. Szokolay, Steven, which states an external sunscreen device is the most effective tool for controlling sun penetration [13].

\section{CONCLUSION}

The facade configuration model has a better influence on the thermal performance of the flat units. The best facade configuration model for the thermal performance of buildings is the facade configuration 1 model which can provide a decrease in air temperature of up to $0.57{ }^{\circ} \mathrm{C}$, with a reduction in the percentage of cooling degrees of $58.09 \%$. Lower performance is produced by facade configuration 2 which has an increase in air temperature of $0.19^{\circ} \mathrm{C}$. The results of this study indicate thermal performance can be obtained through a decrease in temperature, an increase in the percentage of decrease in cooling degree hours, and a comfortable duration periode. Meanwhile the effect of the physiological effects of airflow velocity has not shown significant results.

\section{REFERENCES}

[1] H. Sghiouri, A. Mezrhab, and H. Naji, "Shading devices optimization to enhance thermal comfort and energy performance of a residential building in Morocco," J. Build. Eng., 2018.

[2] S. Subhashini and K. Thirumaran, "A passive design solution to enhance thermal comfort in an educational building in the warm humid climatic zone of Madurai," J. Build. Eng., vol. 18, no. December 2017, pp. 395-407, 2018.

[3] A. Abdeen, A. A. Serageldin, M. G. E. Ibrahim, A. El-zafarany, S. Ookawara, and R. Murata, "Solar chimney optimization for enhancing thermal comfort in Egypt: An experimental and numerical study," Sol. Energy, vol. 180, no. January, pp. 524-536, 2019.

[4] F. Goia, M. Haase, and M. Perino, "Optimizing the configuration of a façade module for office buildings by means of integrated thermal and lighting simulations in a total energy perspective," Appl. Energy, vol. 108, pp. 515-527, 2013.

[5] S. Tong, N. Hien, E. Tan, and S. Kardinal, "Experimental study on the impact of facade design on indoor thermal environment in tropical residential buildings," Build. Environ., vol. 166, no. June, p. 106418 , 2019.

[6] S. Liu, Y. T. Kwok, K. K. Lau, P. W. Chan, and E. Ng, "Energy \& Buildings Investigating the energy saving potential of applying shading panels on opaque façades: A case study for residential buildings in Hong Kong," Energy Build., vol. 193, pp. 78-91, 2019.

[7] M. Mandalaki, S. Papantoniou, and T. Tsoutsos, "Assessment of energy production from photovoltaic modules integrated in typical shading devices," Sustain. Cities Soc., vol. 10, pp. 222-231, 2014.

[8] M. Manzan, Genetic Optimization Of External Fixed Shading Devices, Energy Build., 2014.

[9] L. S.-L. Rendona. L.G.Valladares, Schmid. Gerd, "Review on energy savings by solar control techniques and optimal building orientation for the strategic placement of fac,ade shading systems," Energy Build., 2016.

[10] A. Ghosh and S. Neogi, "E ff ect of fenestration geometrical factors on building energy consumption and performance evaluation of a new external solar shading device in warm and humid climatic condition," Sol. Energy, vol. 169, no. April, pp. 94-104, 2018.

[11] S. Omrani, V. Garcia-hansen, B. Capra, and R. Drogemuller, "On the effect of provision of balconies on natural ventilation and thermal comfort in high-rise residential buildings," Build. Environ., 2017.

[12] A. L. S. Chan and T. T. Chow, "Investigation on energy performance and energy payback period of application of balcony for residential apartment in Hong Kong," Energy Build., vol. 42, no. 12, pp. 2400 2405, 2010.

[13] V. Szokolay, Steven, Introductionto Architectural Science The Basis Of Sustainable Design, Architectu. Britain: Library of congress cataloging in publication data, 2004.

[14] M. and V. Ansley, Architectural Aerodynamics. London: Applied Science Publishers LTD, 1977.

[15] F. Allard, Natural Ventilation Building-A Design Handbook. London: James and James Science Publishers, 1998. 